\title{
Percutaneous endoscopic gastrostomy tube replacement
}

Percutaneous endoscopic gastrostomy (PEG) tube insertion allows provision of long-term enteral nutrition in patients with dysphagia or those not meeting their nutritional requirement. PEG replacement may be required in patients with significant tube degradation or injury. Single esophageal intubation is preferable, to minimize patient discomfort and reduce the procedural risks associated with upper gastrointestinal endoscopy. Previously described methods of PEG replacement include: passage of the thread through the PEG tube, which is held in place by the plastic introducer [1], and passage of the snare through the thread and then around the PEG tube [2]. However, these methods are either complex to perform or have the potential to lose the guide wire or internal bumper during withdrawal. We describe an easy and reliable method of PEG tube replacement.

The external triangular PEG bumper (Fresenius Kabi, Bad Homburg, Germany) is initially moved away from the abdominal wall. The old PEG tube is transected using a 16-gauge venous cannula or larger, approximately $1-2 \mathrm{~cm}$ from the skin surface ( $\bullet$ Fig. 1). After removal of the needle, the silk thread is passed through the lumen of the cannula ( $\mathbf{F i g}$. 2). The plastic cannula is removed from the PEG tube, leaving the thread in situ ( Fig. 3). The thread is then tied securely around the tube. Following this the PEG tube is cut using scissors or a scalpel blade a further $1-2 \mathrm{~cm}$ distal to the thread ( $\bullet$ Fig. 4). A snare is placed around the internal bumper to allow removal of the residual external portion of the PEG tube and attached thread through the esophagus. The new PEG tube is then attached to the thread and inserted in the standard manner.

We have routinely employed this technique for several years without complication and recommend it as a simple and effective method for PEG tube replacement.

\section{Competing interests: None}

Endoscopy_UCTN_Code_TTT_1AO_2AK

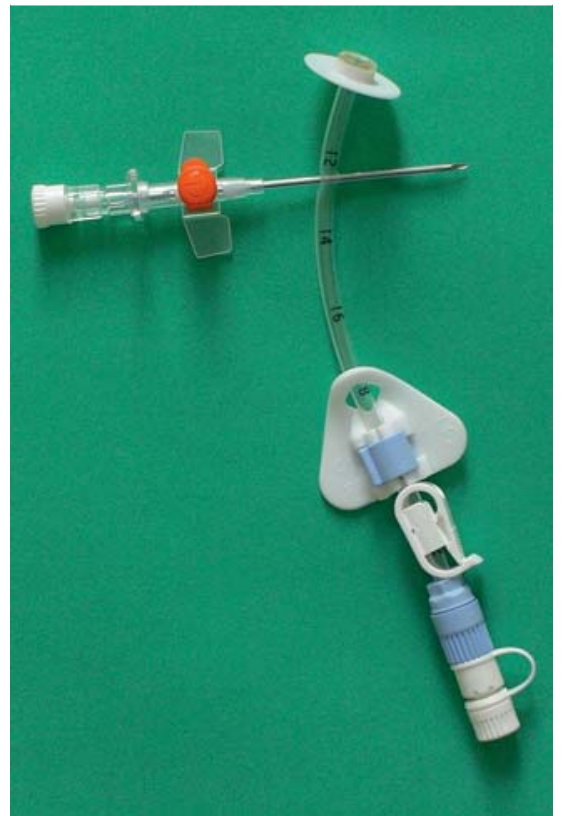

Fig. 1 A venous cannula is used to transect the old percutaneous endoscopic gastrostomy (PEG) tube.

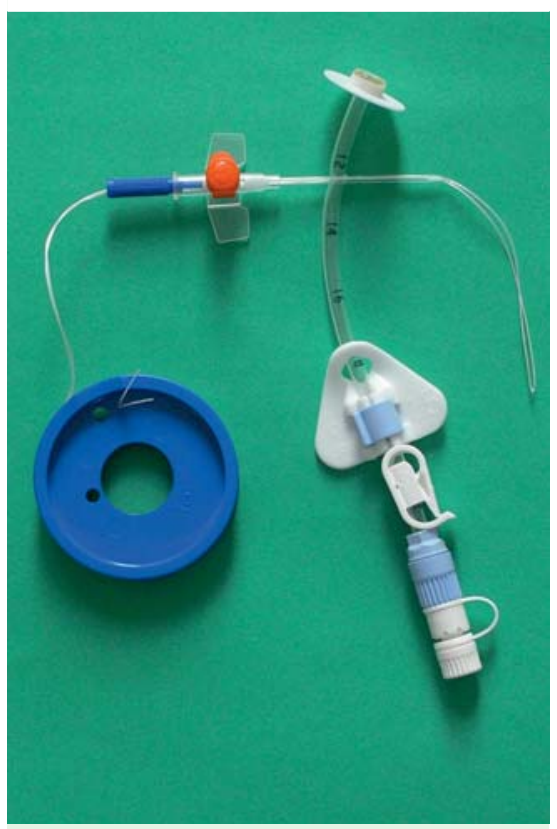

Fig. 2 The silk thread is inserted through the cannula.

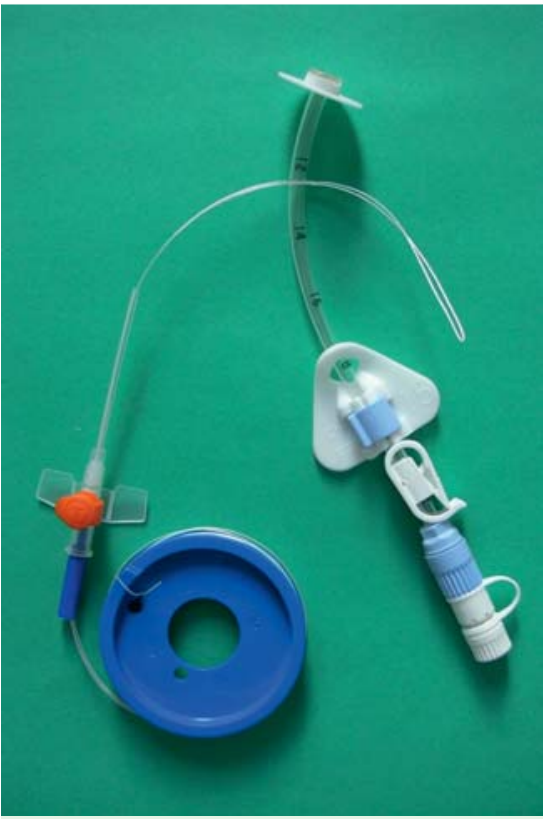

Fig. 3 The cannula is withdrawn from the PEG tube.

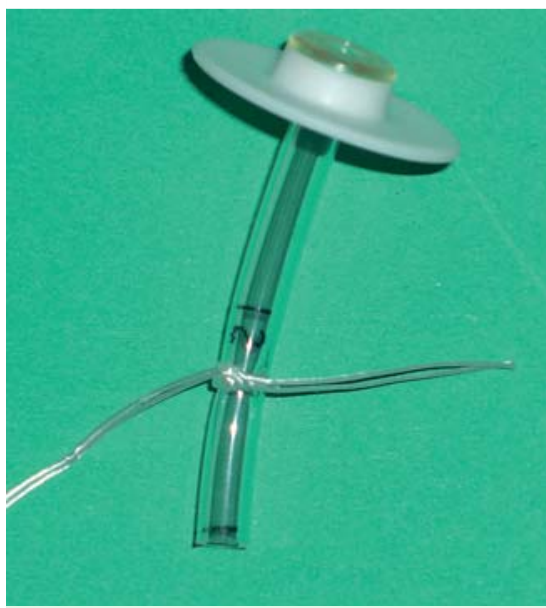

Fig. 4 The thread is tied securely around the PEG tube. The tube is then cut $1-2 \mathrm{~cm}$ below this. 
J. K. Turner, J. W. Berrill, S. Dolwani, J. T. Green, G. Swift

Department of Gastroenterology, University Hospital Llandough, Cardiff, UK

\section{References}

1 Frenz MB, Heinsohn P, Siuda G, Travis SPL. A reliable method of single-pass endoscopic gastrostomy replacement. Endoscopy 2004; 36: 754
2 Javaid B, O'Toole PA. Percutaneous endoscopic gastrostomy replacement: a simple and secure technique for combined bumper and wire retrieval. Endoscopy 2000; 32: S65

\section{Bibliography}

DOI $10.1055 / \mathrm{s}-0029-1244102$

Endoscopy 2010; 42: E146 -E147

(c) Georg Thieme Verlag KG Stuttgart · New York . ISSN 0013-726X
Corresponding author

\section{J. K. Turner}

Department of Gastroenterology University Hospital Llandough

Penlan Road

Llandough

Vale of Glamorgan

CF64 2XX

UK

Fax: +44-2920-715538

jkturner76@hotmail.com 